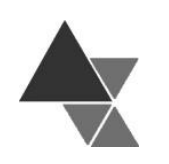

\title{
Práticas e percepções de universitários sobre alimentação: estudo qualitativo utilizando grupos focais
}

\author{
Francini Xavier Rossetti ${ }^{1}$ e Marina Vieira da Silva ${ }^{2}$
}

Aspectos valorativos e atitudinais sobre alimentação entre jovens são pouco conhecidos. O objetivo do estudo foi avaliar práticas e percepções de estudantes sobre alimentação em uma universidade pública. A amostra $(n=31)$ foi composta por estudantes de graduação do 1ㅇ ao 5a ano. Os dados foram obtidos por meio de técnica qualitativa, utilizando-se o método de grupos focais (foram realizados quatro grupos). Os resultados foram analisados utilizando o procedimento de categorização das falas. No tocante ao acesso e disponibilidade à alimentação, os estudantes citaram a conveniência, o preço baixo e variedade do restaurante universitário para a realização das refeições, porém mencionaram a monotonia de sabores como um empecilho à escolha do local. O local de moradia caracteriza-se como o ambiente capaz de modificar seu comportamento alimentar e, associado a comensalidade, promove o consumo de alimentos processados e ultraprocessados. Entre estudantes que saíram da casa da família para fins de estudo, a inabilidade de prover o alimento no domić́lio dificulta a manutenção de hábitos alimentares adequados. O consumo de alimentos "prejudiciais à saúde" esteve associado a produtos processados e ultraprocessados. É necessário criar um ambiente no qual se propicie a adoção de estilos de vida saudáveis e sustentáveis no contexto universitário, propiciando a promoção da qualidade de vida entre os estudantes e por consequência a prevenção das doenças crônicas não transmissíveis e a obesidade.

Palavras-chave: pesquisa qualitativa, comportamento alimentar, grupos focais, estudantes, segurança alimentar e nutricional.

\section{University practices and perceptions about feeding: a qualitative study using focus groups}

Values and attitudes aspects about feeding among young people are little known. The objective of this study was to evaluate students' practices and perceptions about feeding at a public university. The sample $(n=31)$ was composed of undergraduate students from 1 st to 5 th year. Data were obtained using a qualitative technique using the focus groups method (four groups were performed). The results were analyzed using the categorization procedure. With regard to access and availability to food were concerned, students cited the convenience, low price and variety of the university restaurant, but cited the monotony of flavors as a barrier to the choice of the place. The domicile is characterized as the environment able of modifying its eating behavior and, associated with commensality, promotes the consumption of processed and ultraprocessed foods. Among students who left home for study purposes, the inability to provide food at home makes it difficult to maintain adequate eating habits. The

${ }^{1}$ Professora - Faculdades Integradas do Vale do Ribeira (FIVR/UNISEPE). Doutoranda - PPGCTA - ESALQ - USP. Endereço para correspondência: Rua Oscar Y. Magário no 185, Jardim das Palmeiras, Registro, SP, CEP: 11900-000.E-mail: francini@usp.br

2 Professora Doutora - Departamento de Agroindústria, Alimentos e Nutrição. Escola Superior de Agricultura “Luiz de Queiroz”, Universidade de São Paulo. E-mail:marinavieiradasilva@usp.br 
consumption of food "harmful to health" was associated with processed and ultraprocessed foods products. It is necessary to create an environment in which to adopt healthy and sustainable lifestyles in the university context, to promote quality of life among students and consequently, prevention of chronic noncommunicable diseases and obesity.

Keywords: qualitative research, food behavior, focus groups, students, food and nutritional security.

\section{INTRODUÇÃO}

Jovens podem apresentar interesse no tema alimentação, porém esse não necessariamente repercute no comportamento alimentar. Interações complexas entre fatores macrossociais, ambientais e individuais podem influenciar as percepções, motivações e comportamentos relacionados ao comer ${ }^{[1]}$.

Dentre os fatores macrossociais, é amplamente reconhecido que o processo de globalização e industrialização do sistema alimentar ${ }^{3}$ apresenta como uma de suas consequências a homogeneização dos hábitos alimentares[2], marcada pelo consumo excessivo de produtos processados e ultraprocessados ${ }^{[3]}$ e esta tem demonstrado estreita relação com o incremento do excesso de peso e o agravo de doenças crônicas ${ }^{[4,5]}$.

O aumento do consumo de alimentos ultraprocessados entre jovens brasileiros apresenta relação com a baixa renda monetária, a dupla jornada de trabalho e estudo e o consumo fora do domicílio[b]; em relação ao estado nutricional, dados nacionais provenientes da Pesquisa de Orçamentos Familiares (2008-2009) indicam crescimento de mais de 30\% de excesso de peso entre as fases da adolescência e a vida adulta[7].

A compreensão dos fatores macrossociais, ambientais e individuais relacionados aos hábitos alimentares e ao estado nutricional é primordial para o planejamento de ações de prevenção e promoção da saúde entre jovens. A fim de compreender fenômenos sociais relacionados ao consumo alimentar, as pesquisas de natureza qualitativa são dinâmicas e interativas, auxiliando na busca por significados e sentidos dos fenômenos relacionados à alimentação e estilo de vida, com vistas a compreensão de aspectos relevantes entre essa população[8].

Para a presente pesquisa, a noção de sistema alimentar foi considerada para as reflexões na esfera macrossocial, e as condições ambiental e individual, foram investigadas por meio do conceito da segurança alimentar e nutricional ${ }^{4}$, sob a forma como o indivíduo assimila e interpreta o cenário do abastecimento e da disponibilidade de alimentos, formas de acesso e questões relacionadas a nutrição, cultura e saúde.

Neste contexto, o presente estudo teve por finalidade identificar, por meio de grupos focais, as práticas e percepções sobre alimentação de estudantes universitários.

\section{CASUÍSTICA E MÉTODOS}

\section{Recrutamento e participantes}

A percepção de alimentação no contexto da SAN foi avaliada por meio de técnica qualitativa, do tipo descritiva-exploratória, em que os dados foram obtidos utilizando-se a técnica de grupo focal[ ${ }^{8]}$. Entre setembro e outubro de 2014, estudantes da Escola Superior de Agricultura Luiz de Queiroz, Universidade de São Paulo (ESALQ/USP) foram convidados a participar do primeiro grupo focal por meio de comunicação eletrônica, redes sociais e grupos on-line relacionados às atividades dentro do campus. $\mathrm{O}$ folder registrou como título "Conversa aberta sobre segurança alimentar e nutricional" e continha informações referentes ao grupo ao qual se destinava e a técnica utilizada para levantamento dos dados (grupo focal), além de horário, local e contato para inscrição. Os estudantes receberam informações sobre $\mathrm{O}$ oferecimento de um lanche ao final do grupo. A

${ }^{3}$ Pode ser concebido por meio da forma como os alimentos são produzidos, armazenados, processados, distribuídos e acessados pela população.

4 A Segurança Alimentar e Nutricional (SAN) compreende a realização do direito de todos ao acesso regular e permanente a alimentos de qualidade, em quantidade suficiente, sem comprometer o acesso a outras necessidades essenciais, tendo como base práticas alimentares promotoras de saúde que respeitem a diversidade cultural e que sejam ambiental, cultural, econômica e socialmente sustentáveis. 
participação se deu de forma voluntária e os critérios de seleção foram: 1) ser estudante de cursos de graduação na ESALQ; 2) ter entre 18 e 30 anos de idade.

Nos dias e horários programados, os estudantes que aceitaram participar do estudo foram informados dos objetivos da pesquisa e preencheram o Termo de Consentimento Livre e Esclarecido. O projeto de pesquisa foi aprovado pelo Comitê de Ética da Escola Superior de Agricultura Luiz de Queiroz, sob o no 134, de acordo com as exigências éticas e científicas da Resolução no 466 de 2012 - Conselho Nacional de Saúde do Ministério da Saúde[?].

Foram realizados 4 grupos focais, com 6 a 9 estudantes em cada grupo. O número de grupos foi definido de acordo com o critério de saturação das falas, definido como o momento em que informações novas não surgem ${ }^{[10]}$.

A moderação dos grupos foi realizada pela primeira autora da pesquisa, com auxílio de dois pesquisadores assistentes, que tinham como função observar comportamentos não verbais e registrar as falas de modo resumido. A totalidade das falas dos grupos foram gravados com auxílio de gravador de voz e transcritos integralmente. Os participantes estavam cientes da gravação.

\section{Roteiro semiestruturado}

Um roteiro semiestruturado baseado em constructos relacionados ao tema segurança alimentar e nutricional foi elaborado. Temas relacionados aos aspectos de food safety, (tecnológicos, nutricionais e sanitários) e de food security (acesso ao alimento, utilização sustentável, promoção de saúde e cultura alimentar), foram contemplados. Um estudo piloto foi realizado com 8 estudantes e analisado para revisão do roteiro. Após a análise foram adicionados alguns temas considerados relevantes. Os resultados do estudo piloto foram inclusos nas análises posteriores, uma vez que não houve mudanças significativas nos temas.

As questões norteadoras do roteiro final podem ser visualizadas na Figura 1.

Figura 1. Roteiro do grupo focal

1. O que vocês pensam sobre a alimentação dos jovens após a entrada na universidade? Deixar o grupo falar e depois questionar: por que é dessa maneira?

2. Se houve mudanças na sua alimentação, quais foram?

3. Como é a questão do tempo para realizar tarefas relacionadas à alimentação entre os estudantes (compra, preparo de refeições)?

4. É possível manter os hábitos alimentares trazidos de casa?

5. E a questão financeira? Deixar o grupo falar e depois questionar: vocês acreditam que suas situações financeiras (ou que suas famílias proporcionam) influenciam seus hábitos alimentares? Por quê?

6. Quais alimentos ou bebidas com maior frequência de consumo aqui na universidade? Qual o motivo que os levam a escolher esses alimentos?

7. Existem momentos específicos para consumir determinados alimentos ou bebidas?

8. O que você considera um alimento de qualidade?

9. Vocês procuram conhecer a origem do alimento que estão adquirindo e de que forma ele foi produzido? Como (lendo embalagem, rótulo, consultando a internet)? Qual a importância disso?

10. É importante saber que produziu esse alimento - se multinacionais ou agricultores familiares, por exemplo?

11. Quais são os fatores que levam vocês a consumir alimentos orgânicos? E os impeditivos?

12. Vocês consideram que algum ou alguns dos alimentos consumidos são prejudiciais à saúde? Deixar o grupo falar e depois acrescentar: se sim, quais as motivações para o consumo? 


\section{ANÁLISE DOS DADOS}

Os dados transcritos foram analisados pela moderadora da pesquisa, utilizando o procedimento de categorização das falas (identificadas no roteiro da pesquisa): acesso ao alimento, produção sustentável, promoção de saúde e cultura alimentar qualidade tecnológica, qualidade nutricional, qualidade sanitária.

A compreensão das formas pelas quais os estudantes realizam a mediação de seus comportamentos relacionados à alimentação no contexto de SAN baseou-se em um no modelo da teoria cognitiva social desenvolvido com o objetivo de compreender os comportamentos alimentares de adolescentes. Esse modelo foi conceituado em função de quatro níveis de influência que interagem e afetam os comportamentos alimentares: fatores intrapessoais, interpessoais, ambientais e sociais, e considera fatores individuais, ambientais e macrossociais sobre as percepções e práticas relacionadas a alimentação[11].

\section{RESULTADOS}

A amostra foi constituída por 31 estudantes (27 do sexo feminino e 4 do sexo masculino). A composição e caracterização dos grupos estão descritas na Tabela 1.

Tabela 1. Composição e características dos grupos focais, 2014

\begin{tabular}{|c|c|c|c|}
\hline Grupo focal & $\begin{array}{l}\text { Período da } \\
\text { graduação }\end{array}$ & Curso de graduação & $\begin{array}{c}\text { Número de participantes e } \\
\text { sexo }\end{array}$ \\
\hline Grupo 1 - Centro de Vivência & 10 ano & $\begin{array}{c}\text { Ciências dos Alimentos e Engenharia } \\
\text { Florestal }\end{array}$ & 8 (feminino) \\
\hline $\begin{array}{c}\text { Grupo } 2 \text { - Casa do Estudante } \\
\text { Universitário (CEU) }\end{array}$ & $1^{\circ}$ ao $5^{\circ}$ ano & $\begin{array}{l}\text { Engenharia Agronômica, Engenharia } \\
\text { Florestal e Ciências dos Alimentos }\end{array}$ & 9 (5 feminino e 4 masculino) \\
\hline Grupo 3 - República feminina I & $1^{\circ}$ ao 3 - ano & $\begin{array}{c}\text { Biologia, Ciências dos Alimentos, } \\
\text { Engenharia Florestal }\end{array}$ & 8 (feminino) \\
\hline $\begin{array}{c}\text { Grupo } 4 \text { - República feminina } \\
\text { II }\end{array}$ & $1^{\circ}$ ao $4^{\circ}$ ano & $\begin{array}{l}\text { Gestão Ambiental e Ciências dos } \\
\text { Alimentos }\end{array}$ & 6 (feminino) \\
\hline
\end{tabular}

Fatores individuais, ambientais e macrossociais influenciam o comportamento alimentar e atuam mediando o consumo individual[11]. No contexto populacional, a concretização da segurança alimentar e nutricional ocorre de forma semelhante, em níveis de mediação que vão de domiciliar (acesso aos alimentos), ao local/regional (disponibilidade de alimentos), e macro socioeconômico (promoção de saúde, diversidade cultural e sustentabilidade ${ }^{[12]}$.

Dessa forma, os resultados foram descritos de acordo com as categorizações prévias das falas, baseadas nos constructos relacionados ao tema segurança alimentar e nutricional. Vale ressaltar que os estudantes não discutiram de forma aprofundada algumas temáticas, que serão apresentadas no decorrer dos resultados.

\section{Acesso e disponibilidade ao alimento}

No tocante ao acesso e disponibilidade à alimentação, os estudantes citaram o restaurante universitário (denominado por estes como "Rucas") em funcionamento no campus da ESALQ-USP como um local que proporciona o acesso à alimentação. $\mathrm{O}$ estabelecimento oferece refeições no almoço e jantar ao preço de $\mathrm{R} \$ 1,90 /$ refeição (valor em vigor no período relativo à coleta de dados). A variedade de alimentos oferecida pelo estabelecimento foi frequentemente citada: 
facilita muito, por que tem uma diversidade muito maior de alimentos". (Sexo feminino, G3).

No entanto, a variedade de alimentos oferecida pelo restaurante não foi associada à qualidade nutritiva e tampouco houve consenso entre os estudantes sobre a definição de saudabilidade das refeições, uma vez que este conceito foi referido de diversos modos. Entre aqueles que apresentavam a percepção de que as refeições eram nutricionalmente inadequadas, a justificativa se dava pelo tamanho das porções dos alimentos dos quais se serviam e não as preparações em si.

Uma das limitações para a utilização do restaurante referia-se à percepção do tempo limitado do serviço (pouco tempo para realização a refeição) e a monotonia relacionada a falta de sabor dos alimentos.

O acesso a uma alimentação adequada foi identificado como mais dificultosa para os estudantes que viviam na casa do estudante universitário - CEU. A opção por pratos prontos e semiprontos foi frequentemente citada entre os moradores.

"Aqui se você almoça e janta no Restaurante Universitário você tem uma alimentação mais saudável, mas se você não tem tempo de ir lá almoçar...você acaba não tendo uma comida tão saudável, você não faz uma salada, acaba não dando tempo". (Sexo feminino, G3).

No período da coleta de dados a casa estava passando por reformas e dispunha somente de uma cozinha; aqueles que preparavam suas refeições guardavam os mantimentos nos respectivos quartos e tinham que se deslocar nas dependências do prédio de três andares, com todas as provisões para realizar o preparo das refeições.

'Não é chato [cozinhar na CEU), mas é difícil, por que você tem que pegar tudo que tem no quarto, levar tudo lá pra cozinha, e aí "Ai, esqueci de pegar o.... sei lá, qualquer coisa, o óleo", então dá preguiça às vezes. É mais fácil [...] comprar uma comida congelada e descongelar no (forno de) microondas". (Sexo feminino, G2).

Os estudantes afirmam que lograr uma alimentação categorizada subjetivamente como saudável era custosa, à exceção do restaurante universitário, como exemplificado nas falas a seguir:
"Ser saudável é caro. Você vai no supermercado você vai comprar lá, salada, você não deixa de comer o tradicional, o arroz, feijão, carne, você vai acrescentar a salada, você vai trocar o peito de peru ou mortadela ou presunto, que acaba sendo mais caro, então... eu acho que... acaba sendo mais caro". (Sexo feminino, G2).

"O problema é que as vezes a gente vai no mercado ou supermercado, até por essa questão do tempo, você vai no supermercado tem uma saladinha pronta, lavada, picada... é muito mais caro que a alface, você tem que comprar in natura, sabe?" (Sexo feminino, G1)

\section{Comensalidade}

Aspectos relacionados à comensalidade foram frequentemente citados pelos participantes. Os grupos fizeram referência às refeições preparadas em grupo como um momento de lazer. Essas refeições foram associadas a alimentos processados e ultraprocessados. Não houve associação de aspectos relacionados à comensalidade com o restaurante universitário, que é considerado um local frequentado somente para o consumo com vistas ao atendimento das demandas nutricionais.

“É por que batata frita é um evento, né? A gente se reunia todo mundo pra fazer. Eu trazia do meu estágio e a gente fazia". (Sexo feminino, G2).

"[...] daí no sábado, na sexta, acaba saindo com o namorado, então vai comer besteira". (Sexo feminino, G1).

Observa-se que ambiente no qual o estudante está inserido tem capacidade de modificar sua percepção e consumo alimentar, e esse fator parece mais importante do que os hábitos alimentares construídos durante a infância e a adolescência.

\footnotetext{
“Tá, você vai tá comendo salada, você vai olhar pro prato do lado e mais 12 pessoas e vão estar comendo bife frito, batata frita, sabe? Você vai passar vontade... você acaba não sendo mais [...] tão saudável". (Sexo feminino, G1).
}

Por outro lado, as novas experiências e as constantes adaptações levam a novos rearranjos, como pode ser observar na fala registrada a seguir: 
"Eu sempre pensei na minha alimentação, mas não tanto quanto eu penso aqui. E eu acho que cada dia mais que a gente se acostuma... pra mim, principalmente, eu estou me acostumando a essa vida, mas, sei lá... ainda mais dentro de uma república, por exemplo, seus hábitos alimentares vão mudando constantemente". (Sexo feminino, G1).

\section{Fatores individuais}

Apesar de todas as dificuldades relacionadas ao acesso a uma alimentação adequada, condições individuais também foram relevantes nas discussões.

Tendo por base parte dos estudantes que saíram de casa pela primeira vez e que no contexto familiar adotavam uma alimentação adequada, foi possível observar a dificuldade de manter esses hábitos na universidade, uma vez que era um novo dever assumir responsabilidade do autocuidado e da realização de tarefas relacionadas à compra e preparo de alimentos. Dessa forma, após a entrada na universidade muitos destes estudantes não conseguiam manter bons hábitos alimentares durante a vida universitária.

"É que antes, em casa, meus pais ficavam em cima, assim. E aqui não tem mais isso, a gente come se a gente quiser, se a gente tá com fome". (Sexo feminino, G3).

"Eu volto todos os finais de semana pra casa, e daí em casa volta a ter alimentação saudável, é que minha mãe (diz): ah, não vai comer isso, sabe? te incentiva a comer saudável”. (Sexo feminino, G4).

No grupo 3, ("república feminina" I), as participantes citaram uma horta urbana localizada na rua da república (de fácil acesso), mas não haviam realizado visitas/compra ao estabelecimento.

Dentre fatores individuais que podem afetar o alcance de uma alimentação adequada, foram frequentemente citados a falta de autodisciplina, a falta de tempo, inabilidade culinária, conveniência e a percepção de saúde.

“[...] quando você chega numa faculdade você vai atrás de uma república, né? E aí a alimentação não vai mais ser a sua, vai se basear no grupo... então se você quer, sei lá, perder peso, não é o grupo que vai perder peso, é você, então você tem que ir atrás disso você mesmo, sabe?" (Sexo feminino, G1);
"Eu acho que aqui a gente come qualquer coisa [...] sempre tem um chocolate, bala ou doce na mochila. Você tá com fome, você pega e come. Você não tem tempo de fazer alguma coisa". (Sexo masculino, G3).

O estresse causado pelos novos arranjos de vida e decorrentes do curso de graduação levam os estudantes a comer mais.

"[...] e eu também sinto que as vezes eu desconto um pouco o estresse na minha alimentação". (Sexo masculino, G3).

Em todos os grupos houve a afirmação da procura por uma alimentação saudável, e em alguns períodos esse objetivo era alcançado.

“[...] quando eu estava em casa eu comia o que tinha e agora que eu faço comida, eu faço o que eu quero e eu quero o saudável. Mas não agora, que eu tô nessa fase de esfiha. Esse negócio de pedir comida, eu sempre peço, mas se eu for fazer eu faço o saudável". (Sexo feminino, G4).

No grupo focal realizado na "república feminina" I, 6 jovens manifestaram o desejo de tornarse vegetarianas, em razão de almejar a adoção de hábitos alimentares saudáveis, além da preocupação com o meio ambiente e sustentabilidade. A adesão parcial à dieta vegetariana foi justificada devido à falta de tempo para o preparo das refeições, concomitante à preocupação com o bem-estar, uma vez que a carne foi fortemente associada à saúde e envolve rápido preparo, quando comparada a hortaliças e cereais.

Um tema recorrente além da falta de tempo para cozinhar, foi a inabilidade para a preparação de refeições variadas.

"Quando falta o Rucas por greve ou por qualquer outro motivo, ou fim de semana, é... ninguém tem muita afinidade com cozinha, então a variedade, sei lá, cai bastante, né?” (Sexo masculino, G2).

De maneira geral, a falta de habilidades somada à alegada escassez de tempo e a necessidade de economizar (dinheiro) faz com que os estudantes evitem cozinhar. Neste sentido, eles buscam alimentos práticos e baratos, citando frequentemente o macarrão, macarrão instantâneo tipo lámen, linguiça tipo calabresa e ovos como alimentos básicos do cotidiano. 
Por outro lado, observa-se que parte das estudantes alega possuir aptidão na cozinha e, quando procuram priorizar a tarefa, tem maior facilidade para alcançar êxito:

"E daí eu compro [...] basicamente pra semana, daí eu deixo tudo preparado. Deixo a carne temperada, eu faço tudo mais ou menos e daí eu boto no grill e tal... vinte minutos tá pronto o almoço". (Sexo feminino, G1).

A alimentação pode tornar-se um fardo ou ainda, parte do processo de amadurecimento pelo qual passam os estudantes, como nesta fala:

“(...a alimentação) é uma coisa a mais para você se preocupar, mas não necessariamente um peso [...] mas a forma que você tem que encarar isso, é uma forma de amadurecimento". (Sexo feminino, G1).

Quando questionados sobre consumo de alimentos prejudiciais à saúde, todos os grupos foram unânimes em citar alimentos processados, ultraprocessados e bebidas, incluindo as alcoólicas. Os alimentos mais citados foram o refrigerante, doces, biscoitos doces e macarrão instantâneo. $\mathrm{O}$ relato do consumo desses alimentos foi associado à praticidade, como registra um estudante do grupo 3:

"Eu não sou tão chegado em bolacha. Eu preferia comer uma melancia do que comer bolacha". (Sexo masculino, G2).

\section{Segurança do alimento}

Em todos os grupos a qualidade do alimento foi prontamente mencionada como qualidade na produção/processamento. Os estudantes possuem a percepção que quanto menor o grau de processamento, maior a qualidade dos alimentos. Frequentemente citada, mas não de maneira unânime, esteve a produção orgânica.

"Eu acho que é... ele ter um bom processamento assim, que seja... algo natural". (Sexo feminino, G1).

O alimento transgênico, citado somente em um grupo, foi alvo de opiniões reticentes, como pode ser observado na fala a seguir: "[...]a gente não sabe até que ponto aquilo é prejudicial e até que ponto aquilo é vantajoso". (Sexo masculino, G3).

A qualidade também foi lembrada pela questão estritamente nutricional por alguns estudantes. No quarto grupo (república feminina II) essa opinião foi compartilhada por todas.

\footnotetext{
"Eu acho que é equilibrio, né, das coisas que tem dentro (...) não pode ter muito sódio, muita gordura [...] as vezes eles (a indústria) baixam a quantidade de açúcar, mas você vai ver e tem uma quantidade absurda de gordura". (sexo feminino, G4).
}

Um estudante citou a dificuldade de conhecer a qualidade do produto, tendo em vista a relação com a origem e citou a importância dos selos de qualidade nos alimentos. Por outro lado, o maior custo desses alimentos foi considerado um fator impeditivo à aquisição.

“[...] quando a gente não tem ciência da origem do alimento, a gente acaba colocando fé na qualidade do alimento se tem um selo, sabe? Se tiver algum selo é que coloca mais fé que tem qualidade, mas não quer dizer que a gente vai comprar pela questão financeira, que é bem mais caro". (Sexo masculino, G3).

A qualidade no preparo das refeições foi citada como importante, porém, a falta de higiene no preparo das mesmas não se revelou um fator impeditivo ao consumo, como pode ser observado na fala a seguir:

\footnotetext{
"(a falta de higiene) não me impede de comprar, mas eu como de olho fechado". (Sexo feminino, G1).
}

\section{Meio ambiente e sustentabilidade}

No primeiro grupo a questão ambiental não estava presente no roteiro. Nos demais grupos a questão foi discutida de maneira tangencial, em tópicos relacionados às multinacionais e a produção orgânica. Os estudantes se manifestaram parcialmente e poucos tomaram um posicionamento claro em torno da questão.

\footnotetext{
"Depois que eu entrei na faculdade, eu comecei a perceber de outra forma. O que a gente compra, porque a gente compra. Então eu me preocupo bastante com a origem. É... eu tento pensar na parte social disso, na parte política, na parte econômica,
} 
não só de eu estar indo lá pra me alimentar”. (Sexo feminino, G3).

De maneira geral, os estudantes têm a percepção das repercussões socioambientais das suas escolhas, porém, no cotidiano, essas escolhas parecem distantes, seja pela comodidade e conveniência ou mesmo pelo custo dos produtos diferenciados.

"Eu gostaria de poder aplicar mais isso de buscar a origem, só que por convenção você acaba sempre buscando o que é mais prático, o que é as vezes mais rápido. O produtor não é sua prioridade, né". (Sexo masculino, G3)?

Parte dos estudantes considera os alimentos orgânicos como mais adequados, porém esses alimentos não são "convenientes", seja por não estarem prontamente disponíveis para compra ou preparo, ou ainda, têm preço acima da média de um alimento tradicional, como representado na fala a seguir.

"Eu acho que a questão do preço pesa muito assim, sabe, todo mundo gostaria de apoiar os pequenos produtores[...] eu acho que isso é meio que todo mundo pensa assim, mas tanto disponibilidade quanto preço afetam na hora da escolha". (Sexo feminino, G4).

\section{DISCUSSÃO}

A análise qualitativa da percepção da alimentação, balizada pelo conceito de sistema alimentar e de SAN possibilitou reflexões sobre aspectos do comer e percepções associadas ao consumo que perpassam questões individuais e levam a compreensão de elementos socioambientais, especialmente entre jovens no período de transição entre a adolescência e a vida adulta.

A pesquisa qualitativa permitiu a compreensão de uma série de comportamentos e percepções relacionadas à alimentação que podem auxiliar no desenvolvimento de recomendações para essa população sobre saúde e qualidade de vida (ponderadas as peculiaridades locais) e ainda, a observação de comportamentos alimentares focada no contexto social deve auxiliar o desenvolvimento de estratégias de promoção de saúde efetivas entre estudantes universitários (considerando aspectos gerais desta pesquisa).
A técnica de grupos focais permite agrupar indivíduos que compartilham características em comum, reunidos para discutir um tema a partir das experiências vivenciadas, situação que permite $\mathrm{O}$ surgimento de vários pontos de vista. Além do mais, o método possibilita ao pesquisador a captação de significados que poderiam não ser manifestados pelos participantes, a partir de outras técnicas ${ }^{[13]}$. Apesar dos recursos metodológicos disponíveis, poucos estudos nacionais que adotaram grupos focais visando a compreensão de comportamentos relacionados à alimentação no contexto de segurança alimentar e nutricional e, aqueles que o fizeram, a empregaram com grupos populacionais com características distintas aos estudantes universitários ou com objetivo de utilizá-la como ferramenta para construção de escala para avaliação de insegurança alimentar ${ }^{[14,15]}$. O modelo de análise da percepção do comportamento alimentar baseado na teoria cognitiva social foi complacente ao conceito de SAN, dado que ambos consideram as dimensões individual, social e ambiental[11].

Assim como na pesquisa realizada por Nelson et al.[16] o número de participantes do sexo masculino foi restrito e, apesar da metodologia da saturação das falas ter sido utilizada, a representatividade dos resultados entre jovens do sexo masculino pode ter sido limitada.

A passagem da adolescência para a vida adulta - assinalada nesta pesquisa com a admissão em cursos superiores - induz modificações nos padrões de consumo alimentar e podem refletir novas identidades dentro do grupo social, fato observado nesta e em outras pesquisas ${ }^{[17]}$, mas também capital cultural que possibilita novas aspirações em torno dos alimentos considerados adequados ao consumo, como por exemplo, os orgânicos.

O acesso e disponibilidade de alimentos no contexto universitário foi um dos tópicos mais discutidos entre os estudantes. $\mathrm{O}$ restaurante universitário localizado no campus fornece refeições subsidiadas que cumprem a função de nutrir, com variedade de alimentos, mas monotonia de sabores. Dentre 1855 estudantes do sul do Brasil, 45\% estavam insatisfeitos com o sabor e os temperos da comida, apesar de apreciarem o preço, iluminação, localização, limpeza e higiene ${ }^{[18]}$. Os resultados observados sobre a percepção da inadequação do consumo de nutrientes das refeições foram relacionados ao tamanho das porções consumidas (estas eram servidas em bandejas 
que excedem em muito o tamanho de um prato de refeição). Apesar de contextos socioculturais distintos, entre estudantes estadunidenses, o consumo de grandes porções de alimentos oferecidos no buffet contribuía para a percepção negativa sobre a qualidade nutricional[16]; no contexto desse país, desde a década de 1970 houve incremento do tamanho das porções de alimentos ultraprocessados, paralelamente ao crescimento do sobrepeso e obesidade ${ }^{[19]}$.

No Brasil, os restaurantes universitários foram delineados como ferramentas de assistência estudantil para estudantes de baixo poder aquisitivo, a fim de proporcionar o desenvolvimento acadêmico ${ }^{[20]}$. $\mathrm{O}$ restaurante universitário não é identificado como promotor de mudanças nos comportamentos alimentares dos estudantes; o planejamento de ações como a troca de bandejas por pratos (habituais a realidade do estudante) e uma política de compras similar ao que ocorre no Programa Nacional de Alimentação Escolar, com aquisição de alimentos regionais, da agricultura familiar e preferencialmente orgânicos ${ }^{[21]}$, atrelada a ações de educação alimentar e nutricional pautadas na promoção de saúde e sustentabilidade ambiental podem ser avaliadas.

No espaço doméstico, a falta de uma área adequada para cozinhar nas moradias universitárias faz com que o forno de micro-ondas seja eleito como um equipamento que viabiliza o consumo de alimentos poupadores de tempo[22]. Em pesquisa realizada por Poolaban et al.[23] o micro-ondas foi um equipamento comumente encontrado nos quartos das residências estudantis situadas dentro do campus e esteve associado ao preparo de refeições prontas para o consumo. Entre aqueles estudantes que viviam de maneira coletiva, o comportamento de compras coletivo não impele ao consumo de alimentos de alta densidade energética e processados/ultraprocessados, padrão distinto ao encontrado por Alves e Boog ${ }^{[17]}$, que observaram maior consumo de frutas e hortaliças.

Embora com prevalência menor de consumo de alimentos ultraprocessados em comparação aos países desenvolvidos, o Brasil tem apresentado crescimento acelerado em relação ao consumo destes alimentos ${ }^{[24]}$. Em revisão de literatura sobre o consumo de alimentos entre universitários brasileiros, Loureiro aponta o crescente consumo de alimentos prontos para o consumo paralelo ao incremento dos níveis de sobrepeso e obesidade[25].
Ainda no tocante aos aspectos interpessoais da alimentação, a comensalidade desempenha importante influência sobre os hábitos alimentares, preferências e consciência relacionada à saúde dos participantes dessa pesquisa; como em outras análises ${ }^{[16,26]}$. Entre os participantes, a comensalidade é associada ao prazer e lazer, e vivenciada a partir dos alimentos processados e prontos para o consumo. Pesquisa realizada com estudantes da Grécia indicou que morar sozinho ou em repúblicas foi associado a mudanças negativas na alimentação após o ingresso na universidade ${ }^{[22]}$ El Ansari, Stock e Mikolajczyk ${ }^{[27]}$ ao realizarem pesquisa quantitativa com universitários de 4 países europeus, concluíram que o local de residência influencia $\mathrm{O}$ comportamento alimentar dos estudantes; aqueles que viviam com os pais consumiam mais frutas e hortaliças comparados àqueles que viviam longe das famílias.

O consumo de alimentos processados é possibilitado pelas condições ambientais (local de moradia) e interpessoais (comensalidade). $\mathrm{O}$ acesso a alimentos saudáveis por meio do restaurante universitário não agrega todas as dimensões relacionadas à comida, ou seja, aspectos sensoriais ou de comensalidade não são identificados nas refeições oferecidas, as quais cumprem apenas o fator nutricional.

A partir desse panorama ambiental e social, os fatores intrapessoais serão afetados por esse contexto ${ }^{[11]}$. Os estudantes citam a falta de autodisciplina como uma das barreiras ao alcance da alimentação adequada e saudável, porém, essa convicção de falha individual tem alicerces bem delineados no contexto de vida dos estudantes. Em estudos com universitários, a autodisciplina é um dos principais fatores citados como barreira para o alcance de uma alimentação saudável, ${ }^{[26,28]}$ porém, há que se questionar os conceitos de autodisciplina e autonomia no contexto ambiental, de disponibilidade e acesso a alimentos ${ }^{[22,26]}$. Martins et al. ${ }^{[24]}$ referem que alimentos ultraprocessados tem seu consumo favorecido entre as refeições devido à ampla comercialização, estratégias de marketing persuasivas e hiperpalatabilidade.

Ainda, ao que concerne aos fatores individuais, a opção pelo consumo alimentos ultraprocessados perpassa pela conveniência e preço acessível destes produtos além do tempo disponível para realizar refeições. Em suma, os estudantes procuram por alimentos baratos, rápidos e fáceis de preparar[26,29]. Uma vez na universidade, os estudos, trabalhos e 
projetos escolares são priorizados em detrimento da alimentação, resultados semelhantes às pesquisas com estudantes universitários encontradas no Brasil[17] e no exterior $[16,26,28,30]$,

Apesar de baratos e práticos, os estudantes indicaram que alimentos ultraprocessados não seriam adequados para a saúde, ao passo que frutas e hortaliças foram reconhecidos subjetivamente como saudáveis. Observou-se que a noção de alimentação saudável se estrutura em uma polarização entre alimentos "bons" e "ruins", similar aos resultados encontrados no Brasil em pesquisas com adolescentes ${ }^{[31]}$ e adultos ${ }^{[32]}$, porém, alimentos ultraprocessados são "bons" no sentido relacionado ao prazer em comer.

Nesse sentido, os períodos de maior estresse também foram ligados ao consumo alimentar em quantidade superior ou associados à ingestão de junk foods. Esses achados distinguem-se dos resultados obtidos tendo como amostra grupo de estudantes de uma universidade belga; entre esses, uma parte informou que procurava consumir mais frutas e vegetais nos períodos de maior exposição ao estresse[26].

Nesta pesquisa, as condições ambientais e sociais conduzem as escolhas para o consumo de alimentos processados e ultraprocessados. Alguns participantes referem tentativas ocasionais de aprimorar os hábitos alimentares, com posterior volta ao desequilíbrio. Entre encontros e desencontros, os estudantes têm a sensação de estarem "perdidos na transição", conforme citado por Blichfeldt e Gram [33]. Observa-se que a noção de desequilíbrio em relação à alimentação só pode ser observada por quem tem conhecimento e adota parâmetros considerados referencias para a promoção da alimentação e saúde.

Os aspectos relacionados a saúde parecem não ser primordiais nessa fase; o corpo jovem ainda não manifestou os sinais e sintomas das doenças crônicas que costumam estar associados a indivíduos idosos. Observa-se que a percepção da relação entre alimentação e prevenção de doenças crônicas é reconhecida, mas não colocada em prática, apesar de recentes estudos apontarem a relação entre o consumo de ultraprocessados e síndrome metabólica, dislipidemia e obesidade em todas as idades ${ }^{[34]}$. As ações de promoção de saúde devem ser dirigiras aos benefícios imediatos do consumo, em detrimento a ênfase dada as implicações para saúde a longo prazo[23,29].

Um fator pouco explorado em pesquisas brasileiras é a falta de habilidades culinárias dos estudantes no preparo de refeições ${ }^{[1]}$. Um avanço nessa área se dá com a última versão do Guia Alimentar para a População Brasileira, que reconhece a importância das habilidades culinárias como campo relacionado à comensalidade e ao lazer[35], a fim de promover o consumo de refeições saudáveis ${ }^{[3,36]}$.

Observa-se que a segurança do alimento esteve parcialmente associada à produção orgânica. Esses resultados são similares aos da pesquisa realizada por LaCaille et al.[28] com estudantes de universidade americana. Ainda nos Estados Unidos, uma pesquisa indicou que entre universitários, 49\% atribuíram importância à aquisição e consumo de alimentos oriundos de produções alternativas, notadamente a orgânica. A valorização deste item foi associada à melhor qualidade da dieta ${ }^{[3]}$. A higiene dos alimentos e estabelecimentos parecem ser importantes, mas não essenciais. $\mathrm{Na}$ pesquisa quantitativa realizada com os ingressantes da ESALQ, USP[] a importância da higiene em estabelecimentos de alimentação foi citada como importante ou muito importante por $85 \%$ dos ingressantes. Apesar dos grupos focais não terem representatividade por se tratar de amostra de conveniência, levanta-se a hipótese de que respostas socialmente aceitáveis podem ocorrer no preenchimento de pesquisas de cunho quantitativo.

As questões macrossociais relacionadas ao consumo, como meio ambiente e sustentabilidade não foi aprofundada e pode ter ocorrido pela dificuldade dos estudantes identificarem a conexão entre aspectos da vida cotidiana, alimentação e macro ambientes. Outro fator pode ter sido a complexidade do tema e a dificuldade de se expressar em opiniões ou mesmo posicionar-se perante os demais participantes. Gatti[ ${ }^{[8]}$ prevê que isso pode ocorrer, causando entre os presentes expressões monossilábicas e receio de algum comprometimento.

\section{CONSIDERAÇÕES FINAIS}

Após o ingresso na universidade, seja por meio de estágios ou de disciplinas relacionadas à produção de alimentos, os estudantes conhecem a cadeia produtiva, no tocante a diversos aspectos, notadamente aqueles 
relacionados à qualidade, sociais e econômicos. No cotidiano, a vida compartilhada entre colegas permite a incorporação de novos hábitos alimentares e essa influência prevalece em detrimento aos hábitos individuais.

Este estudo permitiu compreender percepções e motivações quanto a comportamentos e práticas relacionadas à alimentação e a segurança alimentar e nutricional, dentre as quais podem ser destacados aspectos ambientais (local de moradia, presença do restaurante universitário), sociais (comensalidade) e individuais (preferências pessoais, tempo, habilidades culinárias) como determinantes do consumo e da percepção da alimentação.

No contexto das mediações de SAN (em relação aos aspectos macrossociais) e em sintonia com a Estratégia Global para Dieta, Atividade Física e Saúde ${ }^{[3]}$, as políticas de alimentação e nutrição destinadas à população em geral devem incluir o incentivo a alimentos saudáveis, como frutas, verduras e hortaliças, seja por meio da redução de impostos ou ainda, pelo desestímulo do consumo de alimentos processados.

No contexto ambiental (local), pequenas mudanças podem repercutir positivamente na concretização de SAN entre os estudantes, como por exemplo, a troca das bandejas por pratos no restaurante universitário, a inserção de informação nutricional referente às preparações e ainda a ações de educação alimentar e nutricional balizadas pelo contexto local.

Faz-se necessário criar um ambiente no qual se propicie a adoção de estilos de vida saudáveis e sustentáveis no contexto universitário, propiciando em primeiro lugar a promoção da qualidade de vida de vida entre os estudantes e por consequência a prevenção das doenças crônicas não transmissíveis e a obesidade.

\section{REFERÊNCIAS}

[1] Mullaney M, Corish C, Loxley A. Exploring the nutrition and lifestyle knowledge, attitudes and behaviour of student home economics teachers: baseline findings from a 4-year longitudinal study. Int. J. Consum. Stud. [Internet]. 2008 [acesso em 18 jul 2018];32(4):314-322. Disponível em: https://onlinelibrary.wiley.com
[2] Godfray HCJ, Beddington JR, Crute IR, Haddad L, Lawrence $\mathrm{D}$, Muir JF, et al. Food Security: The challenge of feeding 9 billion people. Science [Internet]. 2010 [acesso em 18 jul 2018];327(5967):812-818. Disponível em: http://science.sciencemag.org/content/327/5967/812/tab-pdf

[3] Contreras JH. Patrimônio e globalização: o caso das culturas alimentares. In: Canesqui AM, Diez Garcia RW. Antropologia e nutrição: um diálogo possível. Rio de Janeiro: Fiocruz; 2011, p.129-145.

[4] Johns T, Powell B, Maundu P, Eyzaguirre PB. Agricultural biodiversity as a link between traditional food systems and contemporary development, social integrity and ecological health. J. Sci. Food. Agric. [Internet]. 2013 [acesso em 18 jul 2018];93(14):3433-3442. Disponível em: https://onlinelibrary.wiley.com/doi/epdf/10.1002/jsfa.6351

[5] Dernini S, Meybeck A, Burlingame B, Gitz V, Lacirignola C, Debs $\mathrm{P}$, et al. Developing a methodological approach for assessing the sustainability of diets: the Mediterranean diet as a case study. New Medit. [Internet]. 2013 [acesso em 18 jul 2018];12(3):28-36. Disponível em: http://newmedit.iamb.it/share/img_new_medit_articoli/949_ 28-dernini.pdf

[6] Rossetti FX. Consumo alimentar, estado nutricional e percepção de segurança alimentar e nutricional entre estudantes de uma universidade pública [dissertação]. Piracicaba: Universidade de São Paulo; 2015.

[7] Instituto Brasileiro de Geografia e Estatística - IBGE. Pesquisa de Orçamentos Familiares 2008-2009: antropometria e estado nutricional de crianças, adolescentes e adultos no Brasil. Rio de Janeiro: IBGE; 2010.

[8] Gatti B. Grupo focal na pesquisa em Ciências Sociais e Humanas. Brasília: Liber Livros; 2005.

[9] Brasil. Ministério da Saúde. Conselho Nacional de Saúde. Resolução no 466, de 12 de dezembro de 2012. Aprova as diretrizes e normas regulamentadoras de pesquisas envolvendo seres humanos. Diário Oficial da União. 12 dez 2012.

[10] Costa M. Grupo focal. In: Duarte J, Barros A. Métodos e técnicas em pesquisas em comunicação. São Paulo: Atlas; 2008. p. $180-192$.

[11] Story M, Neumark-Sztainer D, French S. Individual and Environmental Influences on Adolescent Eating Behaviors. J. Am. Diet. Assoc. 2002;102(3):S40-S51.

[12] Kepple AW, Segall-Corrêa AM. Conceptualizing and measuring food and nutrition security. Ciên. Saúde Coletiva [Internet]. 2011 [acesso em 18 jul 2018];16(1):187-199. Disponível em: http://www.scielo.br 
[13] Carlsen B, Glenton C. What about N? A methodological study of sample-size reporting in focus groups. BMC Med. Res. Methodol. [Internet]. 2011 [acesso em 18 jul 2018];11(1):26. Disponível em: https://www.ncbi.nlm.nih.gov

[14] Yuyama LKO, Py-Daniel V, Ishikawa N, Medeiros J, Kepple A, Segall-Corrêa A. percepção e compreensão dos conceitos contidos na Escala Brasileira de Insegurança Alimentar, em comunidades indígenas no estado do Amazonas, Brasil. Rev. Nutr. [Internet]. 2008 [acesso em 18 jul 2018];21(Suppl.):53s-63s. Disponível em: http://www.scielo.br

[15] Segall-Corrêa AM, Marin-Leon L. A segurança alimentar no Brasil: proposição e usos da Escala Brasileira de Medida da Insegurança Alimentar (EBIA) de 2003 a 2009. Segur. Aliment. Nutr. [Internet]. 2009 [acesso em 18 jul 2018];16(2):1-19. Disponível em: https://periodicos.sbu.unicamp.br

[16] Nelson MC, Kocos R, Lytle L, Perry C. Understanding the Perceived Determinants of Weight-Related Behaviors in Late Adolescence: A Qualitative Analysis Among College Youth. J. Nutr. Educ. Behav. 2009;41(4):287-292.

[17] Alves HJ, Boog MCF. Comportamento alimentar em moradia estudantil: um espaço para promoção da saúde. Rev. Saúde Pública [Internet]. 2007 [acesso em 18 jul 2018];41(2):197204. Disponível em: http://www.scielo.br

[18] Moreira Junior F, Pafiadache C, Loose LH, Piaia R, Scher VT, Peripolli A, et al. Satisfação dos usuários do restaurante universitário da Universidade Federal de Santa Maria: uma análise descritiva. Rev. Sociais e Humanas [Internet]. 2015 [acesso em 18 jul 2018];28(2):83-108. Disponível em: https://periodicos.ufsm.br

[19] Young LR, Nestle M. The Contribution of Expanding Portion Sizes to the US Obesity Epidemic. Am. J. Public. Health. [Internet]. 2002 [acesso em 18 jul 2018];92(2):246-249. Disponível em: https://www.ncbi.nlm.nih.gov

[20] Imperatori TK. A trajetória da assistência estudantil na educação superior brasileira. Serv. Soc. \& Soc. [Internet]. 2017 [acesso em 18 jul 2018];129:285-303. Disponível em: http://www.scielo.br

[21] Brasil. Lei no 11.947 de 16 de junho de 2009. Dispõe sobre o atendimento da alimentação escolar e do Programa Dinheiro Direto na Escola aos alunos da educação básica. Diário Oficial da União.17 jun 2009.

[22] Papadaki A, Hondros G, Scott J, Kapsokefalou M. Eating habits of University students living at, or away from home in Greece. Appetite.2007;49(1)169-176.

[23] Poobalan A, Aucott L, Clarke A, Smith W. Diet behaviour among young people in transition to adulthood (18-25 year olds): A mixed method study. Health Psychol. Behav. Med. [Internet]. 2014 [Acesso em 18 jul 2018];2(1):909-928. Disponível em: https://www.ncbi.nlm.nih.gov

[24] Martins AP, Levy R, Claro R, Moubarac J-C, Monteiro C. Increased contribution of ultra-processed food products in the Brazilian diet (1987-2009). Rev. Saúde Pública [Internet]. 2013 [acesso em 18 jul 2018];47(4):656-665. Disponível em: http://www.scielo.br

[25] Loureiro MP. Estado nutricional e hábitos alimentares de universitários. Segur. Aliment. Nutr. [Internet]. 2016 [acesso em 18 jul 2018];23(2):955-972. Disponível em: https://periodicos.sbu.unicamp.br/ojs/index.php/san/article/ view/8647612/14849

[26] Deliens T, Clarys P, De Bourdeaudhuij I, Deforche B. Determinants of eating behaviour in university students: A qualitative study using focus group discussions. BMC Public Health [Internet]. 2014 [acesso em 18 jul 2018];14(1):1-22. Disponível em: https://www.ncbi.nlm.nih.gov

[27] El Ansari W, Stock C, Mikolajczyk R. Relationship between food consumption and living arrangements among university students in four European countries - A cross-sectional study. Nut. J. 2012;11(28):1-7.

[28] LaCaille L, Dauner K, J Krambeer R, Pedersen J. Psychosocial and environmental determinants of eating behaviors, physical activity, and weight change among college students: a qualitative analysis. J. Am. Coll. Health. 2011;59(6):531-538.

[29] Hartman H, Wadsworth D, Penny S, Assema P, Page R. Psychosocial determinants of fruit and vegetable consumption among students in a New Zealand university. Results of focus group interviews. Appetite. 2013;65:35-42.

[30] Greaney M, Lees F, White A, F Dayton S, Riebe D, Blissmer $\mathrm{B}$, et al. College students' barriers and enablers for healthful weight management: a qualitative study. J. Nutr. Educ. Behav. 2009;41(4):281-286.

[31] Rodrigues EM, Boog MCF. Problematização como estratégia de educação nutricional com adolescentes obesos. Cad. Saúde Pública [Internet]. 2006 [acesso em 18 jul 2018];22(5):923931. Disponível em: http://www.scielo.br

[32] Diez-Garcia R. Práticas e comportamento alimentar no meio urbano: um estudo no centro da cidade de São Paulo. Cad. Saúde Pública [Internet]. 1997 [acesso em 18 jul 2018];13(3):455-467. Disponível em: http://www.scielo.br

[33] Blichfeldt B, Gram M. Lost in transition? Student food consumption. High. Educ. 2013;65(3):277-289. 
[34] Monteiro CA, Louzada MLC. Ultraprocessamento de alimentos e doenças crônicas não transmissíveis: implicações para políticas públicas. In: Nogueira RP, Santana JP, Rodrigues VA, Ramos ZVO. Observatório Internacional de Capacidades Humanas, Desenvolvimento e Políticas Públicas: estudos e análises 2. Brasília: UnB/ObservaRH/Nesp - Fiocruz/Nethis; 2015. p. 167-180.

[35] Brasil. Ministério da Saúde. Guia alimentar para a população brasileira. 2. ed. Brasília: Ministério da Saúde; 2014.

[36] Larson NI, Perry CL, Story M, Neumark-Sztainer D. Food Preparation by Young Adults Is Associated with Better Diet Quality. J. Am. Diet. Assoc.2006;106(12):2001-2007.

[37] Pelletier JE, Laska MN, Neumark-Sztainer D, Story M. Positive attitudes toward organic, local, and sustainable foods are associated with higher dietary quality among young adults. J. Acad. Nutr. Diet. [Internet]. 2013 [acesso em 18 jul 2018];113(1):127-132.

Disponível em: https://www.ncbi.nlm.nih.gov

[38] World Health Organization. Global strategy on diet, physical activity and health. Roma: WHO; 2004. 